Acta Hispanica (2017) 22: 85-100

\title{
REFLEXIONES SOBRE LA UTILIDAD DE LA NOVELA HISTÓRICA COMO HERRAMIENTA DE DIFUSIÓN Y PEDAGÓGICA
}

\author{
Evaristo C. MARTínez-RAdÍo GARRIDO
}

\author{
Marie Curie Research Fellow en la Universidad de Warwick ${ }^{1}$
}

\begin{abstract}
Resumen: El género literario de la novela, además de ser un elemento de entretenimiento puede constituirse también en una útil herramienta de difusión científica. En este punto, es evidente que, siempre que se utilice con rigor, explica, reconstruye y da a conocer amenamente la esencia de tiempos pasados, conllevando por tanto un remarcable componente pedagógico en el campo de la ciencia histórica.
\end{abstract}

Palabras clave: novela, historia, ciencia, pedagogía, realidad, ficción

\begin{abstract}
The literary genre of the novel, besides being an element of entertainment, can also be a good useful for scientific dissemination. At this point, clearly it could turn into a pleasant tool and helps to reconstruct the essence of past times, having a greater projection in the field of History as long as it meets certain and elementary cases of rigor.
\end{abstract}

Keywords: novel, history, science, pedagogy, reality, fiction

\section{Introducción}

El presente trabajo constituye una reflexión acerca de la relación entre la Historia ${ }^{2}$ y la novela, lo científico y lo creativo, a lo que añadimos el posible carácter pedagógico de la segunda. La oposición o contraste realidad-ficción respecto a la relación entre ambas es bastante compleja, dando pie a numerosas obras, debates y puntos de vista. La bibliografía es abundante y simplemente un análisis de la misma superaría ya la extensión e intención del presente artículo. Aquí mostramos entonces unas reflexiones independientemente de las distintas perspectivas más o menos establecidas o marcadas en las corrientes de este género (sea realista, modernista ${ }^{3}$, posmodernista ${ }^{4}$, etc.). Es decir, fuera

\footnotetext{
${ }^{1}$ Este trabajo responde al proyecto "Prisoners of war between the Bourbon nations and the United Kingdom during the $18^{\text {th }}$ Century: ways of life and humanity in misfortune" ("PriWa"), con base en la Universidad de Warwick y realizándose con fondos del programa de investigación e innovación de la Unión Europea Horizon 2020, Marie Sklodowska-Curie [código 746995].

${ }^{2}$ En el presente artículo distinguiremos entre Historia, en mayúscula en tanto a ciencia, e historia, en minúscula cuando aludamos a un relato.

${ }^{3}$ En la corriente realista, como su nombre indica, una característica es la descripción de la realidad que es lo útil desde el punto de vista histórico. En cuanto a la modernista, independientemente de que pueda contener una pretendida ambigüedad, también contiene una imitación de la vida (que es lo que más nos interesaría), con unos personajes que existan fuera del texto de la novela. Véase Francisco de AYALA, "Características de la novela moderna", https://narrativabreve.com/
} 
Reflexiones sobre la utilidad de la novela histórica como herramienta de difusión y pedagógica

de seguir una línea establecida, intentamos comprender que hay diversas situaciones y contextos que pueden ser reflejados en una novela, la cual, siendo rigurosa respecto a los hechos reflejados, puede constituir una buena herramienta pedagógica. Por tanto, tenemos ante nosotros tres grandes puntos a tener en cuenta: la Historia como ciencia, su adaptación a una historia/relato o novela y su uso pedagógico.

Entonces, partimos de cuál es esa herramienta. Atendiendo a lo recogido de Lukács por José María Merino, la novela histórica como tal habría nacido a principios del siglo XIX coincidiendo con la caída del Imperio Napoleónico. De hecho, podemos ser más exactos, pues se le atribuye una fecha y lugar concretos de partida: el 7 de julio de 1814 en Edimburgo con la publicación de Waverley, de Walter Scott. No obstante, también es cierto que hay obras desde la Antigüedad que mezclan Historia y ficción, incluso con aspectos míticos. Con todo, desde los tiempos de Walter Scott hasta la actualidad se fueron desarrollando y ya se cuenta con considerables trabajos sobre la relación Historianovela; abarcan desde conceptos generales a casos concretos sobre obras o localizaciones geográficas. Así, la bibliografía sobre la misma también es abundante, más a partir de la segunda mitad del siglo XIX hasta el presente ${ }^{5}$. Desde entonces se vivieron cambios en gustos, maneras de entender el uso y la relación entre la ciencia histórica y tal género literario, todo aderezado con distintos contextos políticos y evolución social -y de aquí

2013/11/caracteristicas-de-la-novela-moderna.html, fecha de consulta: 29 de diciembre de 2017. Quizás en menor medida la corriente romántica, al conllevar mayor carga de idealización, aunque sí podría ayudar para comprender ciertas visiones o concepciones de un momento histórico.

${ }^{4}$ Sobre el caso posmodernista, véase, entre otros, Celia FERNÁNDEZ PRIETO, "Novela, historia y postmodernidad", in: Actas del Congreso Literatura e Historia. 20 a 22 de octubre de 2004, Jérez de la Frontera, Fundación Caballero Bonald, 2005, 89-104; Karl KOHUT, "La invención del pasado: la novela histórica en el marco de la posmodernidad”, in: Karl KOHUT (coord.), La invención del pasado: la novela histórica en el marco de la posmodernidad, Frankfurt-Madrid, Iberoamericana Editorial Vervuert, 1997, 9-28. Sobre distintos modelos y funciones de la novela histórica en diferentes momentos históricos, así como su relación con Hispanoamérica, véase Marina GÁLVEZ DE ACERO, "Los modelos de la novela histórica: de la 'verdad' de la historia a la historia como ficción”, in: América: Cabiers du CRICCAL, 34, París, 2006, 167-175.

${ }^{5}$ Como el propio Merino expone: "Es cierto que la Historia, mucho antes de la invención del género, fue estímulo de la ficción. Los poemas homéricos, los cantares de gesta y muchos elementos del romancero viejo, el propio ciclo artúrico, bastantes aspectos del imaginario de Lope de Vega, por poner unos cuantos ejemplos, reflejaban, con connotaciones más o menos legendarias, aspectos de sucesos reales del pasado". El matiz se lo daría que "no obstante, tal vez es ahora cuando por primera vez se puede hacer una visión de novela e Historia en que pueda armonizarse, en algunos puntos, lo que antes parecía irreconciliable. Y es que, desde Aristóteles, la aproximación literaria y la aproximación histórica a la realidad eran radicalmente diferentes, cuando no estaban enfrentadas". José María MERINO, "Novela e Historia", in: 1616: Anuario de la Sociedad Española de Literatura General y Comparada, X, Salamanca, 1996, 61. Carlos PUJOL JAUMANDREU, "Novela histórica", asequible en http://www.culturahistorica.es/novela _historica.html, fecha consulta: 21 de diciembre de 2017. 
que tal bibliografía haya también ido en aumento-. Es por ello que surgiera una diversidad de planteamientos tocantes a las bases de la misma, su uso y conveniencia pedagógica o no, que ahora tratamos. Teniendo en cuenta tales factores, no pretendemos en este artículo hacer un recorrido por cada una de las peculiaridades que conllevan ${ }^{6}$, sino unas reflexiones que aporten un punto de vista que entendemos no está tan contemplado. En este sentido, partimos de y completamos los supuestos previamente planteados respecto a la relación entre ambos campos, la Historia y la novela, con un ejemplo constreñido a un hecho de armas de la Guerra de la Independencia española en un trabajo previo7. Pero ahora buscamos un contexto más amplio para dar a conocer la validez de un trabajo literario como herramienta auxiliar de la ciencia histórica. Esta relación es muy útil para la difusión y reconstrucción de unos hechos pasados en tanto escapa del mundo académico riguroso y poco atrayente al auditorio general, sobre todo si es más joven. Con tal combinación se muestra evidente que se puede llegar a mayor cantidad de público y transmitir unos conocimientos de forma más amena y, por tanto, provechosa, pero siempre con una obligación moral de atenerse a una honestidad de lo expuesto y comprendiendo la diferencia entre la parte real y la imaginaria que la adorna.

\section{La complejidad de la transición de la novela histórica en instrumento pedagógico}

Debemos preguntarnos entonces de qué herramienta hablamos y, por tanto y para empezar, qué es una novela en sentido general. Si acudimos a la RAE de hogaño nos indica que es un género literario y/o una "obra literaria narrativa de cierta extensión". Buscando matices sobre la misma en otra obra de consulta general no española, la Encyclopaedia Britannica aporta alguno, en tanto debe contar con cierta complejidad y tratar imaginativamente con la experiencia humana, algo que sería generalmente "a través de una secuencia conectada de eventos que involucran a un grupo de personas en un entorno específico"8. Por tanto, infinidad de variantes en tanto es imaginario,

\footnotetext{
${ }^{6} \mathrm{Ni}$ menos con una extensa bibliografía que, aparte de estar ya tratada, solo de por sí ocuparía un trabajo que se nos escaparía de espacio y tiempo. Entre otras, véase por ejemplo lo recogido en la página web Cultura Histórica fundada y dirigida por el profesor emérito de Historia Moderna de la Universidad de Barcelona Dr. Fernando Sánchez Marcos: http://www.culturahistorica.es/texts _historical_novel.html, fecha de consulta: 10 de octubre de 2016. Igualmente Andrés Rodrigo LÓPEZ-MARTÍNEZ, "La novela como documento histórico de la cultura: ideas para un consenso", in: Historia Caribe, vol. X, no 27, julio-diciembre 2015, Barranquilla, 199-230.

${ }^{7}$ Evaristo C. MARTÍNEZ-RADÍO GARRIDO, Rubén SÁNCHEZ CUEVA, "Novela, historia y un hecho épico y real: la resistencia de Valliniello en mayo de 1809”, in: Asociación Española de Historia Militar (ed. y coord.): Actas del II Congreso de Historia Militar. Novela Histórica e Historia Militar, Madrid, Ministerio de Defensa, 2016, 211-230.

8 "An invented prose narrative of considerable length and a certain complexity that deals imaginatively with human experience, usually through a connected sequence of events involving a group of persons in a specific setting". Artículo de Anthony Burgess "Novel", asequible en:
}

Acta Hispanica, Hungría 22: 85-100, 2017, ISSN: 1416-7263 | 87 
Reflexiones sobre la utilidad de la novela histórica como herramienta de difusión y pedagógica

depende de la experiencia humana (que ofrece obviamente innumerables contextos, situaciones, mentalidades...) y tal entorno específico, también variable y que dependerá de otros factores culturales, religiosos, políticos, históricos... Pero no sólo esto, pues los mismos pueden dar pie a otros como parte de ellos o sus derivaciones. En suma, lo que es relevante es la capacidad imaginativa del novelista, que luego debe ser filtrada y aprovechada por el profesor/profesor/difusor de la materia que trate para transmitir unas ideas y situaciones al receptor/alumno. Pero esto también variará según la clasificación de la propia novela.

Pues bien, qué abarca, qué comprende, cómo clasificarla si su campo es tan amplio. Ana García Herranz expone que dentro de la novela histórica hay también corrientes: "en casi todos los estudios de novela histórica encontramos muchas y variadas clasificaciones que responden a muchos y también variados criterios en torno a los cuales éstas se construyen”. Con ello, "no existe una única definición de novela histórica que pueda agrupar todas las producciones novelísticas que incluyen un material histórico como elemento estructural de las mismas" 9 . Unido a ello y siguiendo con esta misma autora, la distancia del momento que se quiere reflejar en la obra literaria, respecto al momento en que se escribe, unido al necesario conocimiento del mismo, es un problema de anacronismo que influye ya mismamente en su definición y clasificación ${ }^{10}$. Es evidente que es un factor a tener muy en cuenta tanto para el historiador, el novelista o ya el profesor/difusor de lo que se pretenda mostrar si tiene la mencionada intención pedagógica ${ }^{11}$. Por tanto, la formación del novelista y sus fuentes para salvar tal inconveniente son cruciales.

Por nuestra parte, y respecto a su carácter didáctico, no daremos una visión negativa a pesar de que haya autores, como Ortega y Gasset, que opinan que la novela histórica es un género fallido en su propia esencia, pues para ellos son incompatibles el elemento histórico y el novelesco. Por un lado, como apunta Cascón Dorado "si consideramos el didactismo histórico como rasgo distintivo y estructural de la novela histórica, quizá podamos definir mejor el género y establecer una tipología más coherente que las hasta

https://www.britannica.com/art/novel, fecha de consulta: 22 de diciembre de 2017. En este artículo Burgess también disecciona sus orígenes, tipos y formato.

9 Ana GARCÍA HERRANZ, "Sobre la novela histórica y su clasificación", in: Epos. Revista de filología, 25, Madrid, 2009, 305. Igualmente veáse Kurt SPANG, "Apuntes para una definición de la novela histórica”, in: Kurt SPANG, Kurt Spang, Ignacio ARELLANO, Carlos MATA INDURÁIN, La novela histórica. Teoría y comentarios, Pamplona, Ediciones Universidad de Navarra, 1998, 63-125.

${ }^{10}$ Véase GARCÍA HERRANZ, op. cit., 302.

11 "La representación del pasado histórico en la literatura, concretamente en la novela, obliga a afrontar, quizá antes de cualquier decisión compositiva o estilística, los problemas derivados de la distancia temporal y cultural entre el universo diegético - personajes y sucesos situados en el pasadoy el presente de la producción y de la recepción, esto es, el tiempo del autor y de los lectores. Uno de estos problemas es, sin duda, el anacronismo". Celia FERNÁNDEZ PRIETO, "El anacronismo: formas y funciones", in: Maria de Fátima MARINHO, Francisco TOPA (coords.), Actas do colóquio Internacional Literatura e História, vol. I, Oporto, Faculdade de Letras do Porto, 2004, 249. 
ahora propuestas"12. De este modo, si en la novela caben todos los aspectos de la vida del ser humano ${ }^{13}$, nos interesa lo señalado en su momento por Manuel de la Revilla, quien afirma que la novela se puede dividir en tantos géneros como los diversos aspectos que se puedan expresar en la misma. Es cierto que algún autor distingue otras divisiones o matices. Es el caso de Umberto Eco, que ve tres tipos de novela histórica: el romance, donde el pasado sería un escenario para dar paso a lo imaginario incluyendo universos idealizados, caso de los relatos de Tolkien; los de capa y espada, con personajes reales pero con acciones no recogidas por la Historia; y la novela histórica, "donde no es necesario que entren personajes reales y en donde el afán fabulador no es menor que en los casos anteriores, aunque su sujeción a los hechos refuerza la verosimilitud de lo narrado"14. Estos supuestos que plantea entendemos que son matizables en tanto rigor histórico (de contextos y personajes) y con él una posible labor pedagógica o didáctica ${ }^{15}$. Pero, caso de Umberto Eco aparte, siguiendo con Revilla y respecto a las novelas de fondo histórico, pueden tender a expresar la belleza de los hechos que aborda y, por tanto, se corresponderían con un poema heroico. Pero no solo eso, pues podrían simplemente representar la vida cotidiana de un período histórico, tanto en sus hechos como ideas, con lo cual se asemejarían a una epopeya ${ }^{16}$. Con todo, en la denominada novela histórica, a tenor de este profesor, es predominantemente objetiva y en ella "la narración de los hechos supera al elemento subjetivo y los caracteres se describen y retratan más

\footnotetext{
12 Antonio CASCÓN DORADO, "Novela Histórica e historiografía clásica", in: Revista de Estudios Latinos (RELat), 6, Madrid, 2006, 217.

13 "La novela ofrece un campo tan vasto al escritor, que así caben en él los acontecimientos más vulgares, como los más sublimes; las abstracciones del filósofo grave y profundo, como la ligereza del vulgo superficial". Prólogo de Antonio de TRUEBA y la QUINTANA, El Cid Campeador. Novela histórica original, Madrid, Prats, 1852.

${ }^{14}$ Luis VERES, "La novela histórica y el cuestionamiento de la Historia" in: Espéculo. Revista de estudios literarios, 36, Madrid, 2007, asequible en: http://www.ucm.es/info/especulo/numero36 /novhist.html, fecha de consulta: 9 de noviembre de 2016.

${ }_{15}$ Por nuestra parte, en el caso de atenernos a tales supuestos estrictamente, descartamos el primer caso siempre que se trate de tales universos de ficción, pues entendemos que entonces no seguirían lo que podríamos denominar ciencia histórica pura. Es decir, si se trata de un universo irreal en un contexto imaginario, no puede considerarse Historia. Respecto al segundo, la cuestión sería observar el balance, el peso de las acciones ficticias asociadas a tal personaje real, en tanto que lo pudieran desvirtuar. El tercero sí sería más ajustado a lo que apuntamos en este trabajo.

16 Manuel de la REVILLA, Pedro de ALCÁNTARA GARCÍA, Principios de Literatura General e bistoria de la Literatura española, vol. 1, Madrid, Colegio Nacional de Sordo-Mudos y de Ciegos, 1872, 208. "La novela histórica es la epopeya del siglo XIX, y creemos que sería la de todos los siglos si siempre hubiera gozado del grado de perfección á que ha llegado en nuestros días". Prólogo de TRUEBA, op. cit. Otro punto no es más que novelar recuerdos y experiencias ciertas del propio autor -por curiosas o mismamente como aleccionadoras- o referir los hechos como si lo fueran, caso éste de los conocidos Episodios Nacionales de Benito Pérez Galdós (1873-1912). Véase con ello Fernando CORRADÍ, Historia que parece novela, Madrid, imprenta de José Palacios, 1840.
} 
Reflexiones sobre la utilidad de la novela histórica como herramienta de difusión y pedagógica

bien en su aspecto interior, en su acción sobre lo exterior, en su intervención de los hechos". Sus condiciones la convierten entonces en análoga a las del poema heroico. Para él estamos ante un género de novela tan importante como difícil. Para empezar, precisa de un gran conocimiento de la Historia y de cómo serían tanto el carácter de los personajes históricos como el contexto en el que se mueven, sus hábitos de vida. Este punto es básico para no perder exactitud y, de su mano, el interés. Por otro lado, distingue en ellas dos acciones: una histórica y otra ficticia, ambas encomendadas tanto a personajes históricos como a inventados. Como condiciones inexcusables sería el unir indisolublemente las dos acciones ateniéndose a la verdad histórica, no ya a la verosimilitud. Junto a ello, en esta dificultad expone otros aspectos como el idealizar los personajes históricos pero sin alterar su verdadero carácter; mostrar los personajes ficticios envueltos en el espíritu de la época logrando que parezcan históricos; embellecer e idealizar los hechos; retratar fielmente cómo eran los hábitos de vida pasados y los distintos modos de pensar y sentir en el momento que trata. Pero reconoce que los novelistas no se atienen a estos puntos y con frecuencia falsean claramente la Historia; faltan a una regla que debe ser clara, como el ajustar los personajes históricos y los hechos narrados a aquella. Se debe limitar la libertad de los protagonistas dentro del contexto histórico, mezclándolos pero sin que las acciones imaginadas contraríen los hechos verdaderos ni que los personajes difieran de los históricos dando lugar a un dualismo en la acción. En suma:

"El novelista debe guardar por tanto profundo respeto a la verdad histórica, procurando la mayor verosimilitud en lo ficticio y no atribuyendo a ningún personaje histórico hechos contrarios a su carácter o inconciliables con los que la historia nos refiere de él, ni mucho menos alterando el carácter del personaje so pretexto de embellecerle, hasta el extremo de que solo en el nombre se parezca al que en la Historia hallamos. Respeto absoluto a la verdad histórica; verosimilitud en lo ficticio: tal es en breves términos la fórmula a que debe someterse un novelista"17.

Ahora teniendo en cuenta lo que acabamos de apuntar respecto a la función pedagógica, otro punto a tener en cuenta es si lo que se quiere comunicar tiene un carácter lúdico o prescindible. Al mismo tiempo y por contra, si se trata de algo que deba ser aprendido o, cuando menos, tenido en cuenta por un tiempo más o menos determinado para facilitar o ayudar a una formación (y la obtención de un título académico, por ejemplo) ${ }^{18}$. En este segundo supuesto debemos entonces preguntarnos qué es y cuál es la

\footnotetext{
17 REVILLA, ALCÁNTARA, op. cit., 209 y 210. Sobre un punto de vista de la novela histórica contemporánea, véanse las reflexiones de Joan OLEZA, "Una nueva alianza entre historia y novela. Historia y ficción en el pensamiento literario del fin de siglo", in: José ROMERA, Francisco GUTIÉRREZ, Mario GARCÍA-PAGE (eds.), La novela histórica a finales del siglo XX, Madrid, Visor Libros, 1996, 81-97.

${ }^{18}$ Sobre la pedagogía global enlazando con la literatura, véase el monográfico de la revista Ariel: $A$ review of International English Literature, 46/1-2, Calgary, 2015.
} 
mejor manera de aplicarla. Acudiendo nuevamente al Diccionario de la RAE, nos ofrece dos definiciones. La primera expone que se trata de la "ciencia que se ocupa de la educación y la enseñanza". La segunda sería "en general, lo que enseña y educa por doctrina o ejemplos". Pero ninguna de las dos definiciones explicita a quién se aplica, con qué modo, sobre qué materia ni en qué contexto. Por tanto, es más que evidente que tenemos ante nosotros un panorama complejo en tanto la diversidad de variantes que ofrece. Y esto es porque, análogamente a lo que acabamos de ver respecto a la novela, depende de diversos contextos y sensibilidades, sean políticas, religiosas, históricas, culturales, de grupos más o menos mayoritarios o no insertos en una sociedad, por edades, etc. Por tanto, hay una infinitud de variantes que pueden llegar a ser incluso más o menos contradictorias entre sí. Un ejemplo claro en este sentido es la evolución en los distintos sistemas educativos, sin que haya un consenso claro en los métodos de aprendizaje, tema que también suscita muchos debates y en los que no ahondaremos aquí por razones obvias ${ }^{19}$. Sobre el campo y métodos de la pedagogía hay múltiples obras desde la Antigüedad hasta nuestros días ${ }^{20}$, siempre dependiendo de los diferentes contextos (familiar, grado e institución de enseñanza, sea colegio, universidad, etc., para determinadas profesiones, de ámbito religioso, político... $)^{21}$. Es decir, sobre aquello que debe aprenderse en diferentes materias y contextos.

Así pues, tras los filtros mencionados, la novela histórica ya en sí misma, mas luego su adaptación a una función pedagógica, conlleva un proceso selección de información, análisis y síntesis. Y "el análisis y la síntesis son, como ya sabemos, dos poderosas vías de investigación, dos excelentes medios de conseguir la enseñanza de cualquier objeto. Ambos se han empleado en la de la lectura"22.

\section{E1 objeto novelable, la Historia}

Sánchez Cueva apuntó que algunos aspectos de la visión romántica de viaje al pasado son muy poderosos a la hora de empujar a un estudiante a cursar la carrera de Historia $^{23}$. La reconstrucción de contextos, acontecimientos, personajes o la misma cotidianeidad es un atractivo, un incentivo para excitar el interés en la misma como ciencia. Ahora, en un quid pro quo quizá subjetivo, esa visión romántica se ve afectada por la distancia temporal y análisis científico. A este respecto, lo interesante no es que

\footnotetext{
${ }^{19}$ Un caso claro dado en las últimas décadas es la transformación en los métodos de enseñanza desde aplicar el castigo y fuerza física en el aprendizaje hasta el acercamiento más psicológico a las diversas situaciones particulares de cada alumno. Este es sólo un ejemplo de toda esta complejidad. ${ }^{20}$ Véase por ejemplo Marcos SANTOS GÓMEZ, "Pedagogía, Historia y alteridad", in: Teoría de la Educación. Revista Interuniversitaria, Salamanca, 22/2, 2011, 63-84.

${ }^{21}$ La bibliografía en este campo igualmente es muy abundante.

22 Joaquín AVENDAÑO, Mariano CARDERERA, Curso elemental de pedagogía, Madrid, Imprenta de D. Victoriano Hernández, 1855, 193. Sobre la relación entre instrucción y educación, véase ibídem, 157 y ss.

${ }^{23}$ Véase MARTÍNEZ-RADÍO, SÁNCHEZ CUEVA, op. cit.
} 
Reflexiones sobre la utilidad de la novela histórica como herramienta de difusión y pedagógica

el academicismo sustituya tal visión, sino que la complemente; con el interés latente por la primera, la segunda emergerá casi por sí sola al notarla como viva motivando al investigador. De aquí también y a diferencia del novelista (en su caso), el interés del historiador de comprender el presente mediante el estudio del pasado al ser su consecuencia.

Este sentido de comprender hechos y contextos actuales a través de su pasado, sus posibles orígenes, es muy recurrente en diversas esferas, no solo las académicas, llegando a constituir un arma de doble filo. La utilización de la Historia, convirtiéndola en víctima o en cierto punto agresora ${ }^{24}$ (por tanto, historia en minúscula) es algo común. Por poner un ejemplo claro, su uso en positivo, o la tergiversación intencionada de la misma, es el medio del que se valen y valieron determinadas ideologías políticas en cualquier época, adquiriendo un carácter pseudocientífico y suponiendo de facto un falso argumento o, en el mejor de los casos, una verdad a medias. Otro punto es que la barrera temporal por sí misma, sin ninguna intención de alteración con fines partidistas, también es un obstáculo a tener en cuenta.

Junto a lo que acabamos de apuntar, la tendencia natural de cualquier lector/receptor es interpretar nuestro pasado de forma simplificada, dejando así de lado las variantes de complejidad inherentes al mismo -caso aparte la imposibilidad de abarcarlas todas- y siempre teniendo una idea parcial del momento que se quiera tratar. Las épocas pasadas solo las podemos imaginar y, dentro de la imaginación, se cometen errores. Aunque hubiéramos estado ahí, pasaría por el filtro de la interpretación y experiencias individuales, viéndose el mismo contexto distinto por cada persona. Es evidente que cada una filtra los diferentes contextos en los que está inmersa según sus propias realidades y percepciones (lo que hacen a tal realidad relativa) y esa visión de lo que le rodea no es exacta, porque realidades hay muchas. Además, como decimos, dependen de la persona. Entonces, está claro que un novelista se puede ver también afectado por estos factores que acabamos de mostrar, siendo su obra, por tanto, un apoyo para la difusión de una distorsión. Incidimos nuevamente en que, para que pudiera convertirse una novela en una herramienta de difusión científica, aún dotada de licencias imaginativas, el autor deberá contar con una buena formación o, al menos, buen asesoramiento en el contexto que pretenda mostrar.

Una vez apuntada esta consideración y siempre que aludamos a la ciencia, es de reseñar que los historiadores nos hemos dotado de un método científico aplicado a las ciencias social y humana, de un discurso del desarrollo histórico, de escuelas de análisis, corrientes, interrelación con otras ciencias, etcétera. Hacemos aquí un breve inciso. Partiendo de esta base, puede llegarse a la novela como vehículo, previo planteamiento de una cuestión que quizá resulte básica y tantas veces planteada: ¿cuál es el objetivo de un historiador? El desarrollo del veredicto a tal pregunta puede ser, sin duda, verdaderamente complejo. Por supuesto, la resolución del planteamiento no cabría en una única

24 Incluso en ambas a la vez. Por ejemplo, discursos victimistas tratando de instigar un efecto acción-reacción o una justificación al mismo, un hecho, una tendencia ideológico-política, etc. 
respuesta. Tal cuestión ya fue planteada en su momento por Marc Bloch (1886-1944), en su obra Apologie de l'Histoire ou Métier d'historien (ed. 1949). Afirmaba el creador de la escuela de Annales que no puede estudiarse el universo en su totalidad, de tal modo que, por ejemplo, existe una Historia de nuestro sistema solar, que es la astronomía. Así, la Historia estudia, en modo amplio, lo humano, teniendo en cuenta la colaboración interdisciplinar, entre ciencias. Según Marc Bloch el objeto de la Historia sería el ser humano ${ }^{25}$. Si nos atenemos a esta reflexión, es evidente que coincide con la experiencia humana y, por tanto, con la definición de novela vista unas líneas más arriba. Es decir, hay o puede haber una concomitancia en un fin, en tanto explicación o muestra de un contexto del ser humano, con lo que tal sincronía y su posible binomio pedagógico son lógicos y naturales.

\section{Ciencia y literatura; "literatura científica"}

Llegamos entonces al punto crítico de este trabajo al relacionar el ámbito de la imaginación con el científico, donde los hechos y los datos son, y deben serlo por definición, inmutables. Aquí, por tanto, caben las siguientes cuestiones: ¿tiene cabida el mundo creativo y artístico dentro de la ciencia? De ser así, ¿cómo puede desarrollarse y cuáles son sus límites? ¿Es entonces riguroso el producto de tal combinación?

Pero, sea como sea, detrás del historiador está la tarea de investigación, de aportar, que no sirve de nada si no se da a conocer. En este punto es evidente que se conseguirá difundir mejor por las vías que sean de más fácil comprensión. La difusión, por decirlo de algún modo, es una obligación moral del historiador para con sus conciudadanos. Si no se trata de difundir por un medio de fácil acceso podría caerse en lo que el joven novelista Rubén Sánchez Cueva llegó a calificar como un "academicismo voraz, tenebroso y polvoriento; una especie de consejo de sabios olvidado por el tiempo y la memoria al que recurrir de cuando en cuando para indagar sobre una fecha, una guerra o un personaje"26. Por tanto, en la búsqueda de difundir, nos acercamos, con todos los matices que se quiera, al hecho que podríamos decir olvidado de que antiguamente y durante mucho tiempo la Historia no se escribió en lenguaje científico, sino literario ${ }^{27}$. Algo de esto llegó a nuestros días cuando, sea justo o injusto, divulga más una novela histórica que un ensayo o un artículo científico. Es en el campo literario donde se cultivan los instrumentos capaces de combinar, con mayor eficacia, aquellas dos visiones primigenias: la romántica y la científica. Nos acercamos entonces más a la idea de que "la verdad y la

\footnotetext{
${ }^{25}$ Entre múltiples referencias, vid. Julia MARIANO, "Introducción a la Historia-Marc Bloch", in: CONHISREMI, Revista Universitaria de Investigación y Diálogo Académico, 8/2, Ocumare del Tuy, 2012, 115-122.

${ }^{26}$ MARTÍNEZ-RADÍO GARRIDO, SÁNCHEZ CUEVA, op. cit., 214.

${ }^{27}$ CASCÓN DORADO, op. cit., 217 y 219.
} 
Reflexiones sobre la utilidad de la novela histórica como herramienta de difusión y pedagógica

ficción dependen una de otra en el propósito de lograr la comprensión histórica"28. Mostramos ahora unas consideraciones y problemas a ser salvados respecto a la Historia como ciencia respecto a la novela, para terminar en ésta como herramienta pedagógica.

Las reticencias al respeto de la validez de la novela como facilitadora de un discurso científico vendrían del recelo mostrado respecto a que el género literario, como el cine histórico, no podrán tener nunca pretensiones historiográficas. La razón radicaría en tanto que la forma de construcción del discurso de ambos sería, en principio, muy distinta de la construcción del discurso historiográfico. Aquí, el límite establecido para definir la identidad de un discurso u otro, es decir, de la novela (y/o cine histórico) o de la historiografía, estaría en la demarcación existente entre la verdad y la ficción ${ }^{29}$. Unido a ello, la división entre realidad y ficción podría llevar a sostener el argumento de que la Historia se refiere a hechos verdaderos, al contrario que la ficción, a pesar de que la novela histórica se refiere o puede referir a hechos verosímiles. Tal aseveración, en teoría, liberaría al novelista de la responsabilidad de dar cuenta de la verdad de los hechos narrados ${ }^{30}$. Pero, con todo, ambos campos cuentan con la afinidad de la narratividad y, tanto en uno como en otro, la actitud de quien expone (sea historiador o novelista en nuestro caso), es clave en tanto sería "su mirada, la que los saca del indescifrable desorden [pues ya el historiador selecciona y concede mayor o menor importancia a unos hechos o informaciones sobre otras], para ofrecerlos con una forma concreta" 31 . Abordamos esta problemática por partes.

Para dar respuesta a tales cuestiones y antes de continuar, se ha de destacar un matiz al relacionar novela e Historia/ ciencia $^{32}$. Si bien comprendemos que la función básica de un historiador es la de acercar a la sociedad a momentos, hechos, etapas y épocas determinadas - las haya vivido o coexistido con ellos o no, tanto él como el público al que se dirige-, a través de claves que pudieran escapar al público o la sociedad en general, partimos de dos puntos clave:

\footnotetext{
${ }^{28}$ Rodrigo HENRÍQUEZ VÁSQUEZ, "El problema de la verdad y la ficción en la novela y el cine históricos. A propósito de Lope de Aguirre", in: Manuscrits, 23, Barcelona, 2005, 77.

${ }^{29}$ En lo que hace al pensamiento literario de fin del siglo XX y en cuanto a la ficcionalización de la Historia, nos fijamos en la obra José ROMERA, Francisco GUTIÉRREZ, Mario GARCÍAPAGE (eds.), La novela histórica a finales del siglo XX, Madrid, Visor Libros, 1996, en tanto a las valoraciones que recoge sobre el rebrote de nuevas y viejas formas de novela histórica de éxito mundial tan indiscutible como pueden ser las Memorias de Adriano, Yo Claudio o El nombre de la rosa. Relacionado con el tema que tratamos en el presente trabajo, plantea que podría haber vínculos inexplorados con los debates de la llamada "nueva historia", sacudiendo los cimientos de la historiografía profesional. Se sitúa el origen de ésta en la fundación de la revista Annales en 1929, en París y asociada a los nombres de Marc Bloch y Lucien Febvre. No profundizamos en este hecho al escaparse de nuestro objeto de estudio, pero dejamos la referencia mostrada al interés del lector. ${ }^{30}$ VÁSQUEZ, op. cit., 81.

${ }^{31}$ MERINO, op. cit., 62.

32 Vid. en este punto José CRUZ, "Novela e historia”, in: Letras, 47/71, 2005, Caracas, 11-31.
} 
a) Es cierto que la percepción de la realidad es distinta a según quien la viva y la sienta por circunstancias particulares, pero siempre hay una realidad inmutable y desde la que partir.

b) En el caso de omitir ciertos datos (evidentemente, no baladíes), tendríamos el problema de que los que aportemos puedan conllevar una interpretación errónea ${ }^{33}$.

Con todo, a la hora de hacer Historia, con mayúscula, se debe partir de una honestidad (clave) con el fin de sumergir al lector en una realidad, reconstruyéndole una época o un aspecto de ésta que no vivió o desconoce. O lo que es lo mismo: la función del historiador no es, o no debería ser, adoctrinar ni contar falacias. No obstante, como decimos, si aquí tratamos con la novela, es evidente que el autor sí se puede permitir las licencias imaginativas que considere oportunas para incitar en el lector unas emociones determinadas e, incluso, presentar un relato que, aunque basado en hechos reales, le lleve a una percepción distinta aun de lo que sería lógico o correcto en según qué momento y contexto. Como ejemplo, entre tantos, en este último caso se podría hablar de la novela de Alejandro Dumas Los Tres Mosqueteros (1844), donde un hecho de traición a la Corona es magistralmente presentado como "lo correcto". Por supuesto, al tratarse ya de algo creativo e imaginario, también se podría descartar la cuestión de la "honradez histórica", dándose el caso y, por tanto, de escapar de cierto rigor científico al montar la trama -la cuestión es hasta qué punto puede escapar del mismo- y aquí, precisamente, sí buscar el "convencer" de una determinada postura o idea en su caso, sin perder de vista de que se trata de una novela y, por consiguiente, con los condicionantes que se acaban de mencionar ${ }^{34}$. Esta cuestión de rigor y honestidad es la que podría entrar en conflicto con la artística. La cuestión entonces, está en buscar un equilibrio. En palabras de Patricia Riosalido:

"Un exceso de exigencia de verdad puede hacer caer al autor en un abandono de la poiesis o carácter poético y convertir su obra en historia novelada; mientras que un exceso de ficción literaria, una inventiva exagerada, en la que se dejan por completo de lado los hechos reales o se «falsean», plantea la cuestión de si la obra puede seguir denominándose histórica. En mi opinión, una novela histórica ha de encontrar el equilibrio justo entre la ficción y la realidad histórica conocida, dejando un margen para la fantasía y la creatividad artística. Al fin y al cabo, no deja de ser una obra poética que no ha de perder su componente estético. En la novela

\footnotetext{
33 Teniendo en cuenta que no se puede tener acceso a todos y cada uno de los matices, sensibilidades y situaciones de un momento o contexto histórico.

${ }^{34}$ Es evidente que la Literatura, como cualquier otra expresión artística, puede estar al servicio de determinadas ideologías, afianzamiento de sentimientos y filiaciones patrias, etc., que pueden llegar a alterar incluso a la memoria popular. Se pueden mencionar múltiples ejemplos. Véase con lo que apuntamos Dalibor SOLDATIĆ, "Novela hispanoamericana e Historia", in: Colindancias, Revista de la Red Regional de Hispanistas de Hungría, Rumanía y Serbia, 3, Timisoara, 2012, 117-121.
} 
Reflexiones sobre la utilidad de la novela histórica como herramienta de difusión y pedagógica

histórica hay un acercamiento al pasado que no ha de perder su relación con el presente" 35 .

Enlazamos aquí con el mundo creativo y artístico. Tenemos que insertar aquí otro matiz, en cuanto al dilema surgido en la confección de la, llamémosla, novela histórica científica: el problema del choque de teorías o la no existencia de ninguna. Y ahí entra la conjugación del historiador inmerso como novelista (o al revés): la hipótesis o teoría que uno elabore debe ser creíble, en cuanto que posible o probable. Independientemente de las licencias artísticas del autor, respecto a lo no explicado o lo que no quedó claro en la historia, la existencia de lagunas no debe ser tomada como un escollo, sino como una oportunidad para elaborar una teoría con rigor científico, plasmándola novelísticamente.

Ya nos resta decir que, si nos atenemos a la mera pedagogía, el hecho de leer en general supone un esfuerzo, más en una población joven. Si tenemos en cuenta que la lectura va íntimamente ligada a la enseñanza, la novela bien puede paliar tal dificultad haciendo que la materia que se enseñe penetre de mejor manera en el entendimiento del alumno. Partiendo entonces de los supuestos apuntados más arriba y, como se ha señalado, una buena novela histórica puede alcanzar a un público general de forma más amena dándoles una idea cercana de cómo fue una época, un contexto, unos hechos o un personaje ${ }^{36}$. Por ejemplo, quien conozca los bien documentados Episodios Nacionales

35 Tesis doctoral de Patricia María RIOSALIDO VILLAR, Las novelas históricas posmodernas de los ochenta y el problema de la Historia, presentada en la Facultad de Filología, Departamento de Literatura Española y Teoría de la Literatura de la Universidad Nacional de Educación a Distancia (UNED), Madrid, en 2014, asequible en http://e-spacio.uned.es/fez/view/tesisuned:Filologia-Priosalido, fecha consulta: 28 de diciembre de 2017, 55 .

36 REVILLA, ALCÁNTARA, op. cit., 208. "La novela histórica es la epopeya del siglo XIX, y creemos que sería la de todos los siglos si siempre hubiera gozado del grado de perfección á que ha llegado en nuestros días". Prólogo de TRUEBA, op. cit. Otro punto no es más que novelar recuerdos y experiencias ciertas del propio autor -por curiosas o mismamente como aleccionadoras- o referir los hechos como si lo fueran, caso éste de los conocidos Episodios Nacionales de Benito Pérez Galdós (1873-1912). No entraremos aquí a analizar esta modalidad (vid. con ello, por ejemplo e igualmente, CORRADÍ, op. cit.).

${ }^{36}$ Sobre un punto de vista de la novela histórica contemporánea, vid. igualmente OLEZA, op. cit.

${ }^{36}$ Coincidimos por tanto con lo apuntado por el profesor Augusto Escobar Mesa cuando afirma que "la novela histórica constituye un aporte al dominio literario y es fuente valiosa para los historiadores sociales, de las ideas y mentalidades". Augusto ESCOBAR MESA, "La novela histórica: una contradicción realizada", 3, ponencia presentada en el XIX Coloquio Internacional de Literatura Mexicana e Hispanoamericana, organizado por la Universidad de Sonora y Arizona State University, Hermosillo-México, 12-14 de noviembre de 2003, asequible en: http://www.colombiaaprende. edu.co/recursos/superior/handle/literaturacolombiana/pdf_files/tema10.pdf, fecha de consulta: 18 de noviembre de 2016. Véase aquí Susana MONTEMAYOR RUIZ (coord.), La novela histórica como recurso didáctico para las ciencias sociales, Madrid, Ministerio de Educación Cultura y Deporte, Subdirección General de Información y Publicaciones, 2008. 
de Galdós, se acercará a la mentalidad de la España decimonónica, su situación política, personajes (más o menos idealizados), desarrollo de eventos que marcaron su tiempo, etc. Es decir, que aquel lector de los mismos comprenderá mejor y tendrá nociones más o menos profundas de las etapas o eventos que incluso podríamos calificar de descritos en tal colección. Evidentemente, este hecho se puede aplicar a otras obras y contextos. $\mathrm{Y}$, a través de las vivencias de Gabriel de Araceli o quien toque, se puede entonces instruir sobre el contexto o hechos indicados, caso que merece en nuestra opinión mayor atención y recomendación para un público joven que escaparía de una obra estrictamente académica, haciendo que se imbuya en lo posible en tales contextos reteniendo mejor lo que podríamos calificar de su esencia o, cuando menos, puntos clave $^{37}$. Es decir y por tanto, en su caso convierte a la novela en una muy útil herramienta de un profesor de Historia, facilitándole la labor y encarnándolo en guía de la lectura al poder explicar de forma distendida el objeto abordado, siendo él quien pueda mostrar al alumno las partes de creatividad del autor distinguiéndolas de las inmutables. Es evidente que en este punto enlazamos con un aspecto relevante: si el lector se trata de una persona ya iniciada o no en el tema o materia abordada. De serlo, la lectura es distinta al estar familiarizado con los contextos, personajes, etc. En tal caso, aparte de la consecuente fruición de la misma, probablemente le complete su inevitable interpretación de los contextos y le lleve a formularse otras preguntas o inquietudes, desde literarias, como el estilo de presentación de los mismos, hasta históricas en diversos $\operatorname{aspectos}^{38}$.

\section{Conclusiones}

La novela histórica puede constituirse en un elemento de difusión histórica desde un punto de vista menos estricto académicamente. Hablamos entonces de un válido instrumento para difundir aportes científicos y con rigor y, por tanto, que puede conllevar un carácter pedagógico evidente. Es cierto que no existe un sólo método pedagógico y éste dependerá de diversos factores. También que hay que salvar las distancias entre "lo científico" y lo artístico así como una distorsión insalvable del pasado en tanto "lo real", que no es algo absoluto, como las propias barreras cronológicas o incluso físicas. Pero no cabe duda de que una novela puede constituirse para el difusor o profesor (en su caso) en una herramienta que será más atractiva al receptor o alumnado y, por tanto, que ayude a retener mejor los conceptos básicos del contexto tratado, siempre salvando

\footnotetext{
${ }^{37}$ Como es obvio, no únicamente. Por ejemplo aquellas personas de cierta edad que no hayan podido disfrutar de una formación académica con cierta profundidad, al menos en la ciencia histórica.

${ }^{38}$ Huelga decir que, más si buscamos una función pedagógica, debería diferenciarse lo que es real e imaginario en caso de que el lector no iniciado pudiera llegar a confundirlos. Es más común que éste tome por válido cualquier supuesto o contexto representado por el autor a pesar de que pueda inducir a o transmitir errores de interpretación. Respecto a la formación de los lectores, véase FERNÁNDEZ PRIETO, op. cit., 92 y 93.
} 
Reflexiones sobre la utilidad de la novela histórica como herramienta de difusión y pedagógica

las distancias y dejando claro qué parte es ficción y cuál real. Para ello, al construir el relato, la importancia de la preparación histórica del autor es fundamental, pues otorga veracidad y con ella credibilidad de lo que narra, acerca así más a la realidad del momento abordado, evita distorsiones de perspectiva y concede más seguridad a los hechos. Bien es cierto que no se puede perder de vista que estamos ante un relato imaginario, con mayor o menor campo para la creatividad o ficción, pero siempre debe seguir tales pautas de veracidad. Este punto va ligado a que un historiador debe ser honrado y no tratar de convencer de ninguna ideología concreta o campo subjetivo que saliéndose del ámbito científico, si bien en la novela el autor se puede permitir esta licencia. En tal último caso y en tanto su posible función pedagógica, también debería quedar claro al receptor del relato qué parte es imaginada o interpretada, como acabamos de exponer. De no ser así superaría un espíritu de reflexión (más o menos dirigida) sobre un hecho o época recreada pudiendo llegar a convertirse en un instrumento de distorsión. Este sería el supuesto de la utilización de la novela (extensible al arte en general) al servicio de determinadas ideologías. Adoptaría entonces el carácter de herramienta propagandística, de publicidad y fomento de éstas. Por ejemplo, serviría para elogiar o desprestigiar de la misma manera a un determinado personaje o comportamiento escapando entonces de la neutralidad y objetividad que se supone que deben caracterizar a la ciencia. La cuestión es, nuevamente, hasta qué punto hay voluntad por parte de su creador de ajustarla a la realidad, pero ésta también depende de aspectos no voluntarios. Así, por ejemplo, si el autor es contemporáneo de lo que aborda o no y, en este segundo caso, qué distancia temporal puede mediar entre los hechos que trata y el momento en que lo hace. Sea como sea, el novelista histórico generalmente escribe después de finalizados los mismos, con lo que cuenta con conocer el contexto final al que debe conducir a los personajes.

Con todo lo expuesto, al abordar la relación Historia-novela (o novela-Historia) y su posible aplicación pedagógica, es evidente que muchas de las observaciones pueden ser subjetivas en tanto apreciaciones personales y contextos. Las mismas lo serían al partir ya del propio relato literario y, por tanto, de los filtros y selección de datos, hechos o situaciones que el autor quisiera reflejar. Después, habría otros, más si no es el mismo autor quien debe establecer vínculos y destacar y relacionar unos acontecimientos con otros con tal carácter científico-pedagógico, para comunicar un hecho o un momento histórico y, así, también pueden contar con otro grado de subjetivismo. Pero hemos de insistir en que tal subjetivismo debe ser paliado con la honradez histórica, que tendría su raíz ya en el historiador en este caso, como luego de quien tuviera la función de difusor del momento o hechos abordados. Los tres grandes factores que interrelacionamos, Historia, novela y pedagogía, en sí mismos contienen múltiples variantes y dan pie a otras. Esto es, obtenemos una infinidad de posibilidades que se multiplican exponencialmente por la combinación de las variantes suscitadas por las sensibilidades y percepciones de un momento o hecho histórico, junto con los filtros, tanto del historiador 
como luego del autor de la novela (aún pudiendo ser el mismo) ${ }^{39}$. A esas variantes hay que buscarles una fórmula que transmita un mensaje concreto. Esa es la dificultad que esconde gran parte del talento del novelista y más si luego pretendemos que su obra contribuya a la difusión del conocimiento científico.

Entonces, la novela histórica debe buscar el equilibrio entre la ficción y la realidad y, como género literario, dejando a la par un margen para la creatividad artística o incluso académica -en tanto apuntar posibles hipótesis explicativas de un contextoque atraiga al lector. De esta manera es cuando se convierte en útil material pedagógico. Así, humaniza cuestiones que pueden ser muy frías si se atienen generalmente a datos de bibliografía histórica y fuentes de archivo. El historiador los interpreta para hacerlos comprensibles y, en este caso, el novelista hace lo mismo, si bien aportándole comportamientos, frases, movimientos... De este modo, dándoles aliento vital con la posibilidad añadida de explicar en ocasiones lagunas que no aparecen ni en fuentes ni en bibliografía (sin riesgo académico). Obviamente, con todas las precauciones debidas y teniendo claro que se trata de una interpretación. Es decir, la novela puede cumplir la función de "dar vida", por así decir, a unos datos que por sí solos se mostraran fríos y lejanos de un público general. Esto es lo que los haría más comprensibles y asimilables.

Por otro lado, en este género se pueden abordar grandes hechos, pero dentro de éstos los hay menores, que no por serlo dejan de contar con atractivo y son novelables, haciendo que una parte de la Historia más general aparezca atractiva al público. Así, vivencias personales, microhistorias... Un hecho, aunque sea menor, puede dar una imagen de lo que era global y, con ello, hacer la Historia general más cautivadora desde lo particular ${ }^{40}$. Junto a ello, la novela no es necesaria y simplemente un útil para comprender toda una etapa histórica o un contexto en su totalidad. Esto es evidente. No obstante, sí podemos fijarnos en éstos incluso a través de fragmentos de la misma para acercarnos a ejemplos de modos de sentir o determinados personajes o contextos concretos con cierto grado de subjetividad por parte de quien los vivió. Por poner un ejemplo claro, si nos acercamos a una visión de las mentalidades o política de los nacionalismos, aun detalles autobiográficos de un autor a través de la novela romántica en el siglo XIX. Está claro que es probable que en estos casos no se lleve a una recreación objetiva de un momento histórico, pero sí nos acercaría a conceptos presentes en el mismo. Por tanto, también "personajes" o, cuando menos, características de éstos que pudieron ser compartidas en mayor o menor grado por un grupo social o una comunidad. Es decir, acercarnos a una visión y concepciones de un momento dado; ese "qué sentían" o "cómo lo veían" los propios coetáneos,

\footnotetext{
${ }^{39}$ Y más si después se utiliza tal obra literaria con una función pedagógica.

${ }^{40}$ Interesante lo que enlaza en este sentido y sobre un México novelado lo apuntado por Carmen IGLESIAS, "Historia y novela. La región más transparente, de Carlos Fuentes", in: Carlos FUENTES (et al.), La región más transparente. Edición conmemorativa, México, Real Academia Española-Asociación de Academias de la Lengua Española, 2008, 550.
} 
Reflexiones sobre la utilidad de la novela histórica como herramienta de difusión y pedagógica

aunque no fuera general. Está claro en este supuesto que no se debería generalizar y nuevamente, si se utiliza como elemento pedagógico, debe quedar claro que son apreciaciones subjetivas ${ }^{41}$.

${ }^{41}$ Entraríamos en lo que podríamos denominar "subjetividad objetiva". Esto es, subjetividad por parte de quien tiene unas determinadas sensaciones, concepciones y pensamientos, variables en la persona o una comunidad o grupo social; objetiva en tanto es lo que sentía y lo que se comunica sin intento de engaño por parte, en su caso, del profesor o difusor.

100 | Acta Hispanica, Hungría 22: 85-100, 2017, ISSN: 1416-7263 